\title{
The use of both internal thoracic arteries for coronary revascularization increases the estimate of post-operative lower limb ischemia in patients with peripheral artery disease
}

Linda Renata Micali ${ }^{1 \dagger}$, Massimo Bonacchi ${ }^{1,2+}$, Daniel Weigel ${ }^{1 \dagger}$, Rosie Howe ${ }^{1}$, Orlando Parise ${ }^{1}$, Gianmarco Parise ${ }^{1}$ and Sandro Gelsomino ${ }^{1,2^{*}}$ (i)

\begin{abstract}
Background: Patients with a history of peripheral arterial disease (PAD) undergoing coronary artery bypass grafting (CABG) exhibit higher rates of complications. There are conflicting data on the survival benefits for bilateral thoracic artery (BITA) grafting compared with left internal thoracic artery (LITA) CABG in patients with PAD. The aim of the study was to explore the influence of the use of BITA grafts vs. LITA for CABG on post-operative acute lower limb ischemia (ALLI) and main post-operative complications in patients with concomitant PAD.
\end{abstract}

Methods: We used a propensity-score (PS) based analysis to compare outcomes between the two surgical procedures, BITA and LITA. The inverse probability of treatment weighting PS technique was applied to adjust for pre- and intra-operative confounders, and to get optimal balancing of the pre-operative data. The primary outcome was the estimate of postoperative ALLI. Secondary outcomes included overall death and death of cardiac causes within 30 days of surgery, stroke and acute kidney disease (AKD).

Results: The study population consisted of 1961 patients. The LITA procedure was performed in 1768 patients whereas 193 patients underwent a BITA technique. The estimate of ALLI was 14\% higher in the BITA compared to the LITA $(p<0.001)$ group. Thirty-day mortality, cardiac death, occurrence of stroke and AKI did not differ significantly between the groups.

Conclusions: The use of both ITAs led to a significant increase in ALLI. This result was most likely caused by the complete disruption of the ITA collateral providing additional blood supply to the lower extremities. Based on our data, BITA should be used with extreme caution in PAD patients. Further research on this topic is necessary to confirm our findings.

Keywords: Coronary disease, Peripheral artery disease, Limb ischemia

\footnotetext{
*Correspondence: sandro.gelsomino@maastrichtuniversity.nl

${ }^{\dagger}$ Linda Renata Micali, Massimo Bonacchi and Daniel Weigel contributed equally to this work.

'Department of Cardiothoracic Surgery, Cardiovascular Research Institute Maastricht - CARIM, Maastricht University Medical Center, 6229, ER, Maastricht, The Netherlands

${ }^{2}$ Careggi Hospital, Florence, Italy
}

(c) The Author(s). 2020 Open Access This article is licensed under a Creative Commons Attribution 4.0 International License, which permits use, sharing, adaptation, distribution and reproduction in any medium or format, as long as you give appropriate credit to the original author(s) and the source, provide a link to the Creative Commons licence, and indicate if changes were made. The images or other third party material in this article are included in the article's Creative Commons licence, unless indicated otherwise in a credit line to the material. If material is not included in the article's Creative Commons licence and your intended use is not permitted by statutory regulation or exceeds the permitted use, you will need to obtain permission directly from the copyright holder. To view a copy of this licence, visit http://creativecommons.org/licenses/by/4.0/. The Creative Commons Public Domain Dedication waiver (http://creativecommons.org/publicdomain/zero/1.0/) applies to the data made available in this article, unless otherwise stated in a credit line to the data. 


\section{Introduction}

The prevalence of coronary artery disease (CAD) among patients with peripheral arterial disease (PAD) is as high as $60 \%[1,2]$, and $10-30 \%$ of patients who are treated for CAD by surgical interventions suffer from PAD [3, 4].

Patients with a history of PAD who undergo coronary artery bypass grafting (CABG) exhibit higher rates of complications [5]. Therefore, the selection of an appropriate surgical technique is of the outmost importance [6]. In particular, the choice of revascularization strategy and the graft selection are key factors for the success of procedures in these patients.

While large studies have reported a survival benefit for bilateral thoracic artery (BITA) grafting compared with left internal thoracic artery (LITA) CABG $[7,8]$ there is conflicting data published from other studies [9-14]. There is even more uncertainty into the choice of coronary revascularization strategy in the case of PAD patients. As a result, no precise guidelines on graft selection exist for this important subpopulation of patients, and the choice of using one or two thoracic arteries is left to the surgeon's judgement.

We explore the influence of the use of double thoracic artery grafts on post-operative limb ischemia (ALLI) and on the main post-operative complications in patients with PAD.

\section{Methods}

Ethical Committee approval was waived due to the retrospective analysis nature of the study according to National Laws regulating observational retrospective studies (Italian law nr.11960, released on 13/07/2004).

All consecutive patients with PAD undergoing isolated CABG between 1997 and 2019 were included in the analysis. Subjects with previous or concomitant vascular surgery were excluded from the study. A total of 1961 subjects represents the final study population.

The patients were divided into two groups based on the use of the LITA $(n=1768)$ or BITA $(n=193)$ technique.

Clinical PAD was defined as patients who, at the time of CABG including one or more of the following criteria: claudication with exertion or rest; documented aortoiliac occlusive disease, documented abdominal aortic aneurysm or documented noninvasive testing, including ankle-arm index (AAI).

To ascertain high-quality reporting, we followed the guidelines in the article Strengthening the Reporting of Observational Studies in Epidemiology (STROBE), specifically modified for propensity-score research. The list of items addressed are shown in the Supplementary Material.

The main endpoint was ALLI defined as any ischemic event of the arterial system of the lower limbs following the Inter-Society Consensus for the Management of Peripheral Arterial Disease (TASC II) [15]. The secondary endpoints were: (a) death, being defined as death of any cause occurring in or outside the hospital setting within 30 days after the intervention or $>30$ days if within the same hospitalization period, (b) cardiac death being defined as death attributed to cardiac events; (c) stroke characterized as a neurological deficit lasting $>24 \mathrm{~h}$, being CT or MRI confirmed and assessed by a neurologist; and (d) acute kidney disease defined as a post-operative creatinine level of $>200 \mathrm{mmol} / \mathrm{L}$ or the demand for dialysis.

\section{Surgical details}

The LAD and its branches were the target for the skeletonized in situ LITA. Whereas, the target for the skeletonized in situ RITA of the remaining components of left coronary artery were selected according to the following criteria: in patients with two branches allowing for grafting, the primary target was the branch with a bigger perfusion area; if both branches did not differ in terms of dimension of perfusion area, the target for the RITA grafting was the distal branch and the other vessel was revascularized with composite, sequential ITA grafts or alternatively other conduits. The surgeons performing the procedure kept the pleurae closed in order to preserve the communicating bifurcation of the ITAs to the chest wall and to protect the branches of the pericardiophrenic artery. During the procedure, the free flow of the ITAs was assessed. As it was $>50 \mathrm{~mL} / \mathrm{min}$ in all cases, all ITAs were utilized.

\section{Statistical analysis}

Propensity score (PS) inverse-probability of treatment weighting estimation was used [16-19]. Balance was tested either graphically or by means of balance tables. In the model, absolute standardized mean differences (ASMD) were calculated using a cutoff of less than 0.20 for bias statistics. The average treatment effect among the treated (ATT) was chosen as the causal effect estimand of stroke. R software v. 3.6.1 packages were used for analysis. More details can be found in the Supplemental Material (Statistical notes).

\section{Results}

Assessment of balance by boxplots

We found that a good balance was achieved with 1000 iterations (Fig. 1a). The PS distribution (Fig. 1b) for the LITA group ranged from 0.0 to 0.2 , whereas for the BITA group, the distribution ranged from 0.05 to 0.36 , showing a substantial overlap among the two groups. The absolute standardized difference (ASMD) (Fig. 1c) without weighting was below 0.2 in all cases with the highest equaling -0.17 . After the weighting procedure, 

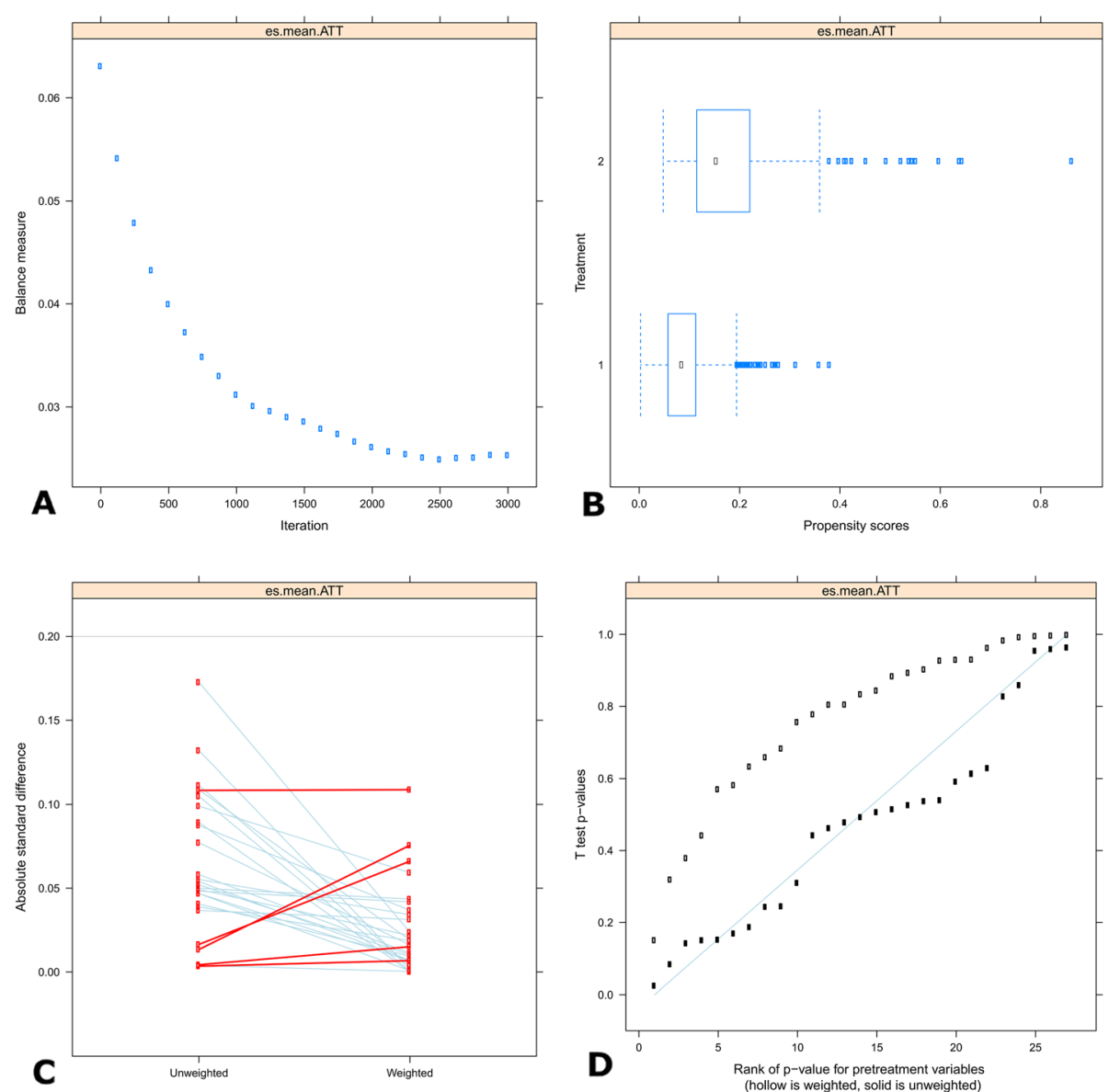

Fig. 1 a. Optimize plot. The plot is a graphical display of the balance criteria as a function of the GBM iteration. The graph demonstrates that a favorable balance was achieved with 1000 iterations and that such a balance was worse with a higher number of iterations that, thus were unnecessary. b. Overlap Assessment. The figure presents two sets of box plots of PS distributions. An overlap between the groups is desirable meaning that there are no values of the pretreatment variables that occur only in one of the treatment conditions. However, there are no specific rules for what constitutes sufficient overlap so, in doubtful cases the combination of the overlap plot and the balance table are used. In our model there is a good overlap between the two boxplots. c. Standardized Effect Size plot. It assesses the balance of pretreatment variables before and after weighting. It shows the maximum pairwise ASMDs. The ASMDs cutoff for defining unbalanced variables was 0.20 . The light blue line represents pretreatment covariates for which the maximum pairwise ASMD reduced after weighting. The red lines mean the pretreatment covariates for which the maximum pairwise ASMD increased after weighting. A good balance is obtained when, after weighting in the majority of variables the ASMDs are $<0.20$ and there is a prevalence of light blue lines. In our model, after weighting the pretreatment variables, the balance showed excellent results with all ASMD values being well below 0.2. $\mathbf{d}$. Quantile-quantile (Q-Q) plot. This plot also assesses the balance of pretreatment variables. In the plot, the Kolmogorov-Smirnov p-value is plotted against the rank of $p$-value for pretreatment variables. Along a 45 degree fitting line, open symbols represent weighted covariates and solid symbols represent unweighted covariates. A good balance is obtained when open symbols lie close, below or above, the 45-degree line. After weighting, in our model, all covariates were well above the reference line

the highest value was 0.11 ; therefore, the ASMD was much lower than 0.2 for all cases. The Q-Q plot (Fig. 1d) before weighting already showed a good balance with all plots being close to the diagonal. After weighting, nearly all of the $p$-values were located well above the diagonal, thereby illustrating a good balancing of the characteristics among the two groups.

\section{Assessment of the balance table}

The balance table (Table 1) showed that the highest standard effect size (std.eff.sz) differences before weighting were found for two vessel disease (-0.17), three vessel disease (0.13), previous percutaneous transluminal coronary angioplasty (PTCA) (0.11), dialysis $(0.11)$, stroke history $(-0.11)$, carotid stenosis $>50 \%$ (0.1), and left ventricular ejection fraction (LVEF) (0.1). After weighting, the highest std.eff.sz was 0.11 (dialysis).

\section{Unweighted early outcomes}

The early crude outcomes by the procedure performed are shown in Table 2. In the unweighted population, there was a higher estimate of ALLI in the BITA group 
Table 1 Balance of patient characteristics $(n=1961)$

\begin{tabular}{|c|c|c|c|c|c|c|}
\hline \multirow{2}{*}{+2} & \multicolumn{3}{|c|}{ Unweighted } & \multicolumn{3}{|c|}{ ATT Weighted } \\
\hline & $\begin{array}{l}\text { LITA } \\
n=1768\end{array}$ & $\begin{array}{l}\text { BITA } \\
n=193\end{array}$ & $\overline{\text { std.eff.sz }}$ & $\begin{array}{l}\text { LITA } \\
n=1768\end{array}$ & $\begin{array}{l}\text { BITA } \\
n=193\end{array}$ & $\overline{\text { std.eff.sz }}$ \\
\hline Age & 70.44 & 70.48 & 0 & 70.6 & 70.48 & -0.02 \\
\hline Gender (Male) & 0.81 & 0.77 & -0.09 & 0.79 & 0.77 & -0.04 \\
\hline Hypercholesterolemia & 0.65 & 0.68 & 0.05 & 0.68 & 0.68 & -0.01 \\
\hline Hypertension & 0.79 & 0.81 & 0.05 & 0.81 & 0.81 & 0.01 \\
\hline COPD & 0.1 & 0.12 & 0.05 & 0.11 & 0.12 & 0.04 \\
\hline Diabetes & 0.4 & 0.42 & 0.05 & 0.41 & 0.42 & 0.02 \\
\hline Diabetes with Insulin & 0.18 & 0.18 & 0 & 0.18 & 0.18 & -0.01 \\
\hline Dialysis & 0.02 & 0.04 & 0.11 & 0.02 & 0.04 & 0.11 \\
\hline AKD & 0.1 & 0.09 & -0.05 & 0.08 & 0.09 & 0.04 \\
\hline Active Smoke & 0.55 & 0.57 & 0.04 & 0.57 & 0.57 & 0.01 \\
\hline Stroke History & 0.06 & 0.04 & -0.11 & 0.04 & 0.04 & 0 \\
\hline TIA History & 0.07 & 0.09 & 0.06 & 0.08 & 0.09 & 0.03 \\
\hline Carotid Stenosis $>50 \%$ & 0.14 & 0.18 & 0.1 & 0.16 & 0.18 & 0.06 \\
\hline Antiplatelet drugs & 0.3 & 0.27 & -0.08 & 0.28 & 0.27 & -0.02 \\
\hline LVEF & 50.16 & 51.28 & 0.1 & 51.27 & 51.28 & 0 \\
\hline $\mathrm{NYHA} \geq 3$ & 0.26 & 0.26 & 0 & 0.26 & 0.26 & 0 \\
\hline IABP & 0.02 & 0.02 & -0.04 & 0.01 & 0.02 & 0.02 \\
\hline Previous PTCA & 0.37 & 0.42 & 0.11 & 0.42 & 0.42 & 0.02 \\
\hline LAD Stenosis & 0.93 & 0.94 & 0.05 & 0.94 & 0.94 & 0.01 \\
\hline MCA Stenosis & 0.38 & 0.4 & 0.06 & 0.4 & 0.4 & 0.01 \\
\hline Three vessels disease & 0.71 & 0.76 & 0.13 & 0.76 & 0.76 & 0 \\
\hline Two vessels disease & 0.29 & 0.22 & -0.17 & 0.23 & 0.22 & -0.02 \\
\hline Pulmonary Hypertension & 0.08 & 0.08 & 0.01 & 0.06 & 0.08 & 0.08 \\
\hline REDO & 0.15 & 0.12 & -0.09 & 0.12 & 0.12 & 0 \\
\hline \multicolumn{7}{|l|}{ Surgery } \\
\hline Elective & 0.63 & 0.65 & 0.04 & 0.66 & 0.65 & -0.03 \\
\hline Urgency & 0.05 & 0.06 & 0.02 & 0.04 & 0.06 & 0.07 \\
\hline Emergency & 0.32 & 0.3 & -0.05 & 0.3 & 0.3 & 0 \\
\hline
\end{tabular}

Abbreviations: LITA Left internal thoracic artery; BITA Bilateral internal thoracic artery; COPD Chronic obstructive pulmonary disease; AKD Acute kidney disease; TIA Transient ischemic attack; LVEF Left ventricular ejection fraction; NYHA New York heart association (functional class); IABP Intra-aortic balloon pump; PTCA Percutaneous transluminal coronary angioplasty; LAD Left anterior descending; MCA Main coronary artery. REDO Re-operative surgery

compared to the LITA group $(34.7 \%$ vs. $19.3 \%, p<$ 0.001). No other differences were detected between the two groups. There were 69 sternal wound infection, 33 $(17 \%)$ in the BITA and $36(2.0 \%)$ in the LITA Groups, respectively $(p<0.001)$.

\section{Main endpoint and secondary endpoints in the weighted population}

After weighting, the estimate of ALLI was higher at $14 \%$ in the BITA compared to the LITA group. $(+14 \%$ compared to LITA (95\% Confidence Interval [CI] 7.0-22.0\%) $p$-value <0.001) (Fig. 2). The weighted secondary endpoints are shown in Table 3. Neither the occurrence of death $(+1.3 \%$ vs. LITA $(95 \%$ CI -1.6 to $4.2 \%) p$-value $=$
$0.37)$ nor cardiac death $(+1.4 \%$ vs. LITA ( $95 \%$ CI -0.9 to $3.7 \%) \quad p$-value $=0.23$ ) significantly differed between the LITA and BITA groups. The comparison of the estimate of stroke $(-0.3 \%$ vs. LITA $(95 \% \mathrm{CI}-3.7$ to $2.9 \%)$ $p$-value $=0.81)$ and the appearance of post-operative acute kidney disease (AKD) (+ $1.4 \%$ vs. LITA $(95 \% \mathrm{CI}-$ 3.0 to $6.0 \%) p$-value $=0.57)$ were not significantly different between the two groups.

\section{Discussion}

The main aim of this study was to analyze the influence of two different CABG techniques involving the use of single or double thoracic arteries on the occurrence of post-operative ALLI in patients with PAD. The 
Table 2 Post-operative data

\begin{tabular}{lllll}
\hline & Overall & LITA & BITA & $\boldsymbol{p}$ \\
\hline & $\boldsymbol{n}=\mathbf{1 9 6 1}$ & $\boldsymbol{n}=\mathbf{1 7 6 8}$ & $\boldsymbol{n}=\mathbf{1 9 3}$ & \\
ALLI & $408(20.8)$ & $341(19.3)$ & $67(34.7)$ & $<0.001$ \\
ALLI treatment & & & & \\
$\quad$ Thrombectomy & $89(21.8)$ & $74(21.8)$ & $15(22.4)$ & \\
Fasciotomy & $67(16.4)$ & $56(16.4)$ & $11(16.4)$ & \\
Endarterectomy & $10(2.5)$ & $5(1.5)$ & $5(7.5)$ & \\
Percutaneous intervention & $126(30.9)$ & $108(31.7)$ & $18(26.8)$ & \\
Surgery & $83(20.3)$ & $68(19.8)$ & $15(22.4)$ & \\
Others/Unknown & $33(8.1)$ & $30(8.8)$ & $3(4.5)$ & \\
Death & $67(3.4)$ & $59(3.3)$ & $8(4.1)$ & 0.71 \\
Cardiac Death & $31(16)$ & $26(1.5)$ & $5(2.6)$ & 0.38 \\
Stroke & $121(6.2)$ & $111(6.3)$ & $10(5.2)$ & 0.56 \\
AKD & $276(14.1)$ & $252(14.3)$ & $24(12.4)$ & 0.561 \\
\hline
\end{tabular}

Values are expressed as $\mathrm{n}(\%)$ or median [interquartile range]. Abbreviations: LITA Left internal thoracic artery; BITA Bilateral internal thoracic artery; ALLI Post-operative limb ischemia; AKD Acute kidney disease

importance of PAD as a predictor of reduced long-term survival and increased risk for complications following CABG has been sufficiently documented [4, 20-23]. Any final conclusion is far from being drawn as to whether a specific technique may help in improving the outcomes and, more specifically, whether the use of the double mammary artery technique is the right choice for these patients when considering its established advantages [9-13].

The main finding of our paper was the significantly higher ALLI estimate in patients receiving a BITA graft $(+14 \%(7-22 \%))$. To the best of our knowledge, our report included the largest collection of patients with PAD undergoing $C A B G$ surgery, focused on the occurrence of post-operative ischemia related to bilateral ITA harvesting.

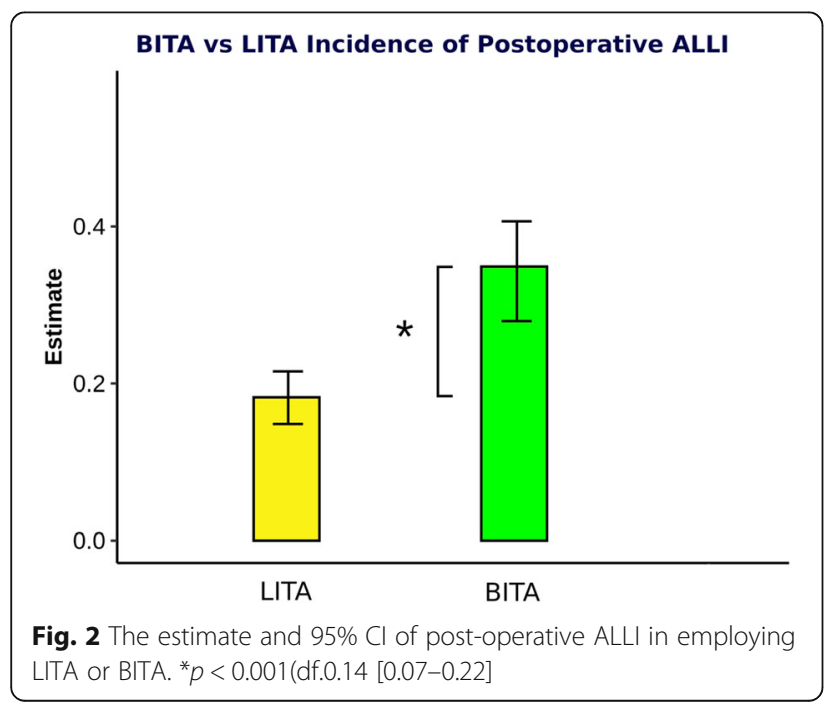

Table 3 ATTs Treatment Group Means

\begin{tabular}{llll}
\hline & Estimate & $\mathbf{9 5 \% ~ C l}$ & $\boldsymbol{p}$-value \\
\hline $\begin{array}{l}\text { Death } \\
\text { ATT Weighted }\end{array}$ & & & \\
$\quad$ (Intercept) & 0.028 & $0.019,0.036$ & $<0.001$ \\
BITA & 0.013 & $-0.016,0.042$ & 0.37 \\
Cardiac Death & & & \\
ATT Weighted & & & \\
$\quad$ (Intercept) & 0.011 & $0.006,0.017$ & $<0.001$ \\
$\quad$ BITA & 0.014 & $-0.009,0.037$ & 0.23 \\
Stroke & & & \\
ATT Weighted & & & $<0.001$ \\
(Intercept) & 0.055 & $0.044,0.067$ & 0.81 \\
BITA & -0.003 & $-0.037,0.029$ & \\
AKD & & & $<0.001$ \\
ATT Weighted & & $0.09,0.12$ & \\
$\quad$ (Intercept) & 0.11 & $-0.03,0.06$ & 0.58 \\
BITA & 0.014 & &
\end{tabular}

Note: The intercept represents the estimate of the respective endpoint in the LITA group. The BITA group estimate illustrates the change in estimate, compared to the intercept, expressed in percent increase or decrease Abbreviations: Cl Confidence interval; LITA Left internal thoracic artery; BITA Bilateral internal thoracic artery; AKD Acute kidney disease

To date, few case reports have highlighted this potential complication after CABG [24-30]. Hirose et al. [31] presented 13 patients with concomitant aortoiliac occlusive disease with collateral circulation via unilateral or bilateral ITA(s). Furthermore, Ben-Dor et al. [29] observed a collateral flow from one or both internal mammary arteries to an occluded or stenotic iliac artery in 15 patients undergoing diagnostic coronary angiography.

Nakatsu et al. [23] found, in 136 patients, a significant increase in post-operative percutaneous transluminal angioplasty but not in surgical revascularization procedures after BITA-CABG procedures. The development of postoperative ALLI is highly predictive of adverse events and mortality [32] but, despite this, there is no robust, controlled analysis on expected outcomes in patients with ALLI after CABG surgery related to the technique employed.

Our data provided clear evidence for the first-time for the increased estimate of ALLI employing BITA in a large patient population.

Chronic aortoiliac occlusive disease induced the development of several collateral arterial pathways that derive from a common embryologic origin [33]. These pathways can be systemic-systemic or visceral-systemic. The Winslow pathway [34, 35] is a systemic-systemic pathway that links the internal thoracic artery, superior epigastric artery, inferior epigastric artery, and external iliac artery and is prominent in aortoiliac obstructive 
disease [36]. This pathway provides more than $40 \%$ of the arterial flow needed to perfuse the lower extremities [37]. ITAs are also involved into the systemic-systemic intercostal artery collateral pathway being connected, through the superior and inferior abdominal epigastric arteries, to the external iliac artery through a network of lumbar and iliolumbar arteries [35].

Parashara et al. reported [38] a patient where the left ITA supplied the left external iliac artery. The main visceral-systemic collateral network includes the mesenteric arteries, the artery of Moskowitz, and the marginal artery of Drummond connected with the internal iliac artery through the superior rectal artery branches and the middle rectal artery branch, with both originating from the inferior mesenteric arteries. These vessels can also communicate with the systemic circulation through branches of the femoral and external iliac arteries. Other visceral-systemic pathways involve the gonadal arteries, arising from the renal arteries or from the aorta [35].

In the case of PAD, the relative contribution of each of these collateral pathways in preserving limb perfusion is unknown [24] and depends on the location and severity of the aortic occlusion. The Winslow pathway is the most important flow supply to the lower extremities, and cases of lower limb ischemia have been reported following ITA harvesting in patients with aortoiliac occlusive disease [39-41]. Therefore, the pre-operative identification of arterial collateral pathways is recommendable in patients with PAD.

Conventional angiography may fail to reveal this collateral pathway, and lower extremity run-off is better visualized during subclavian and/or internal thoracic arteriography than during aortography [42]. Routine visualization of the ITAs before bypass surgery is usually considered unnecessary. Selective angiography of the ITA requires a relatively long period of exposure time, and may result in infrequent complications, such as dissection or embolization with subsequent cerebrovascular ischemia [31]. However, selective ITA angiography can reveal significant proximal subclavian artery stenosis and, when it is performed, allows the visualization of intra-abdominal anastomoses in the presence of highly developed superior and inferior epigastric arteries and of large ITAs [43], which has been directly related to the severity of aortoiliac disease [37, 44].

However, as complication rates are low, and significant findings are often found [45, 46], selective ITA injection is advisable in potential candidates for CABG, in subjects with aortoiliac occlusive disease, subjects with a history suggestive of PAD, subjects where clues of such a condition were available from the patient's medical history, subjects with an absent or weak femoral pulse, and in subjects with an abnormal AAI or absolute ankle perfusion pressures. CT angiography methods can also show the opacification of these arteries with a contrast agent, yielding a reliable visualization of the Winslow pathway [30].

Duplex scanning and directional Doppler are another option to reveal this collateral pathway, demonstrating the reversal of blood flow in the inferior epigastric artery [36].

Our findings seem to discourage the use of bilateral ITA in PAD patients. The higher estimate of ALLI in our BITA patients indirectly confirms that the disruption of the left and right collateral Winslow routes would significantly increases the risk of severe postoperative limb ischemia. This acute interruption might not allow the activation of other secondary pathways as it occurs in chronic occlusions. In addition, with a large caliber of the ITAs during the intra-operative harvesting, the diameter of the ITA may hint towards collateralization via the ITAs [28], and, in this case, the preservation of at least one ITA and the use of alternative conduits is advisable. The cardiac surgeon should also investigate whether the patient had previous abdominal surgery as this collateral pathway could be accidentally ligated during renal and scrotal interventions. Post-operatively, we recommend a close follow-up with screening for the clinical signs of reduced limb perfusion in combination with ABI-measurements [47]. In the case of patients with a stable angina, aorto-iliac revascularization before CABG is an option to be evaluated [31]. The advantages are that, after revascularization of the leg, the ITAs can be used, and the presence of large ITAs becomes a benefit for the patient.

The secondary outcome analysis demonstrated no difference in either short-term overall or cardiac-related mortality. Our data is in accordance with a small study among patients with PAD undergoing either LITA or BITA procedures that did not find any significant difference in in-hospital mortality [23]. Another single center study, analyzing the effect of BITA against LITA augmented with radial artery grafts, in a cohort of PAD patients, demonstrated no significant difference with regard to the 30-day survival [48]. A meta-analysis on the topic suggested an increased short-term mortality, which was attributed to a higher risk for post-operative complications and, in particular, deep sternal wound infections [12]. Our findings were not in accordance with this data.

Although not specifically evaluating the PAD subpopulation, a recent, large RCT comparing LITA vs. BITA found no difference in the long-term mortality [10]. Those results contradicted the many observational studies that suggested a BITA superiority [12, 13, 49]. As Gaudino et al. [50] described, results speaking in favor of the BITA approach may be attributed to nonmeasured confounders rather than to a true superiority 
of the procedure. The evidence is high that the shortterm survival is not significantly different among the two procedures and is generally rather low (a 30-day mortality of $1.2 \%$ ) [51-53]. Whether the mortality rates begin diverging after 5-10 years, as stated by Ryan et al. [54], remains a matter of debate. Warranting further research is the finding by Efird et al. [55], who noticed that black patients with PAD undergoing CABG had higher mortality rates compared to a matched white population.

The occurrence of stroke did not significantly differ between the subgroups during the first 30 days postoperatively. The estimate of stroke in our study population was approximately $5 \%$; which is much higher than the $2 \%$ estimate for stroke reported in the regular CABG population [56]. This could be attributed to PAD being an independent risk factor for stroke development following CABG, thereby posing a generally higher risk for cerebrovascular accidents in our patient population [21, 57]. Nonetheless, we could not establish a link between the applied grafting method and stroke. Bearing in mind the therapy recommendations for patients at risk for periprocedural stroke, for instance antiplatelet therapy and atrial fibrillation screening [58], from our findings there seems not to be a contraindication for the use of both ITAs with respect to the causation of stroke. Finally, this study did not show a significant discrepancy in the development of post-operative acute kidney disease (AKD) among the two subgroups. This is an important finding, as even minor post-operative changes in kidney functioning are associated with a highly increased risk for development of endstage renal disease as well as mortality [59-61]. Generally, PAD patients are at risk to develop AKD not only because this patient group has a high prevalence of diabetes but also because generalized atherosclerosis is an independent risk factor for AKD development [62]. The high prevalence of renal artery stenosis of $23-42 \%$ in PAD patients further substantiates the relationship between PAD and renal disease [1]. This indicates that PAD patients are at risk as it was demonstrated that pre-intervention kidney disease is an independent predictor of worse outcomes and increased mortality following CABG [20]. In line with our findings Nakatsu et al. [63] demonstrated no statistically important effect from LITA vs. BITA procedures on the long-term survival in patients with pre-operative endstage renal disease. Consequently, with respect to the hazard inherent to cardiac surgeries, BITA would appear equally as safe as other CABG methods.

\section{Limitations}

This study has some limitations that need to be highlighted. First, the paper carries the inherent limitations of retrospective observational studies. Nonetheless, the PS multifactor method allowed us to have a population with the absence of baseline unbalances and, at the same time to retain all the patients, leading to a large population study. Second, no stratification was performed between the different types of PAD. In consequence, it cannot be excluded that the BITA group population had a higher estimate of aortoiliac stenosis, thereby biasing the measured outcome. Also, it was not possible to test whether the contribution of collateral pathways in preserving limb perfusion depends on location and severity of occlusions and whether there was any difference between aortic and iliac artery occlusions.

Moreover, the ITA diameters, being an important indicator for collateralization, were not documented as the patients did not undergo routine direct ITA visualization. Pre- and post-operative images would be a valuable source for further evaluation of the effect of BITA on ALLI.

Third, not all patients Underwent ankle-arm index evaluation. Fourth whereas we identified cases on the basis of the definition of ALLI, limited data are available beyond this definition regarding details, severity, or timing of each patient's ALLI.

Fifth, cardiac embolization, as a possible reason for ALLI, was not specifically evaluated. Sixty, our study did not account for the adherence to therapy and the evaluation of the risk factor profile in the respective study populations. This may have added a bias to our results as the importance of risk factors and pharmacological treatment should not be underrated. Seventh, no comparison was carried out with patients undergoing limb revascularization before CABG. However, this was beyond the aim of this study and will be the object of further research. Eighth, we did not perform an external validation, and this might affect the generalizability of our findings.

Finally, it is possible that patients with more severe PAD were selected for BITA to avoid.

wound healing issues following saphenous vein harvesting. This might have introduced a bias and, since we do not have information regarding the severity of PAD, it is was impossible to address this problem of residual confounding in the statistical analysis.

\section{Conclusions}

The usage of both ITAs increased the development of ALLI in patients with PAD. Additional prospective trials are necessary in order to confirm our findings.

\section{Supplementary information}

Supplementary information accompanies this paper at https://doi.org/10. 1186/s13019-020-01315-8.

\footnotetext{
Additional file 1.
} 


\section{Abbreviations}

AAl: Ankle-arm index; AKD: Acute kidney disease; ALLI: Acute lower limb ischemia; ASMD: Absolute standardized mean difference; BITA: Bilateral internal thoracic artery; CABG: Coronary artery bypass grafting; CAD: Coronary artery disease; ITA: Internal thoracic artery; LITA: Left internal thoracic artery; PAD: Peripheral arterial disease; PS: Propensity score; PTCA: Percutaneous transluminal coronary angioplasty

\section{Acknowledgements}

We thank the MDPI English Editing Service for the English revision of the manuscript.

\section{Authors' contributions}

This study was designed by SG. Data was acquired by MB, DW, RH and analyzed by OP and GP. All authors contributed to the interpretation of the data, vouch for the data and analysis, contributed to the writing of the manuscript, and agreed to publish this study. LM, MB and DW authored first drafts of manuscript. SG and LM substantively revised the manuscript. All authors read and approved the final manuscript.

\section{Funding}

None to be declared.

\section{Availability of data and materials}

The datasets used and/or analyzed during the current study are available from the corresponding author on reasonable request.

\section{Ethics approval and consent to participate}

Ethical Committee approval was waived due to the retrospective analysis nature of the study according to National Laws regulating observational retrospective studies (Italian law nr.11960, released on 13/07/2004).

\section{Consent for publication}

NA

\section{Competing interests}

None to be disclosed.

Received: 10 July 2020 Accepted: 21 September 2020

\section{Published online: 25 September 2020}

\section{References}

1. Norgren L, Hiatt WR, Dormandy JA, et al. Inter-society consensus for the management of peripheral arterial disease (TASC II). J Vasc Surg. 2007; 45(Suppl S):S5-67

2. Ishihara T, lida O, Tosaka A, et al. Severity of coronary artery disease affects prognosis of patients with peripheral artery disease. Angiology. 2013;64: 417-22.

3. Rihal CS, Eagle KA, Mickel MC, Foster ED, Sopko G, Gersh BJ. Surgical therapy for coronary artery disease among patients with combined coronary artery and peripheral vascular disease. Circulation. 1995;91:46-53.

4. van Straten AH, Firanescu C, Soliman Hamad MA, et al. Peripheral vascular disease as a predictor of survival after coronary artery bypass grafting: comparison with a matched general population. Ann Thorac Surg. 2010;89: 414-20

5. Collison T, Smith JM, Engel AM. Peripheral vascular disease and outcomes following coronary artery bypass graft surgery. Arch Surg. 2006;141:1214-8.

6. Karthik S, Musleh G, Grayson AD, et al. Coronary surgery in patients with peripheral vascular disease: effect of avoiding cardiopulmonary bypass. Ann Thorac Surg. 2004;77:1245-9.

7. Taggart DP, D'Amico R, Altman DG. Effect of arterial revascularisation on survival: a systematic review of studies comparing bilateral and single internal mammary arteries. Lancet. 2001;358:870-5.

8. Kurlansky PA, Traad EA, Dorman MJ, Galbut DL, Zucker M, Ebra G. Thirty-year follow-up defines survival benefit for second internal mammary artery in propensity-matched groups. Ann Thorac Surg. 2010;90:101-8.

9. Pevni D, Ben-Gal Y, Mohr R, et al. One or two internal thoracic grafts? Longterm follow-up of 957 off-pump coronary bypass surgeries. Ann Thorac Surg. 2017;104:70-7

10. Taggart DP, Benedetto U, Gerry S, et al. Bilateral versus single internalthoracic-artery grafts at 10 years. N Engl J Med. 2019;380:437-46.
11. Thuijs D, Head SJ, Stone GW, et al. Outcomes following surgical revascularization with single versus bilateral internal thoracic arterial grafts in patients with left main coronary artery disease undergoing coronary artery bypass grafting: insights from the EXCEL trialdagger. Eur J Cardiothorac Surg. 2019;55:501-10.

12. Weiss AJ, Zhao S, Tian DH, Taggart DP, Yan TD. A meta-analysis comparing bilateral internal mammary artery with left internal mammary artery for coronary artery bypass grafting. Ann Cardiothorac Surg. 2013;2:390-400.

13. Yi G, Shine B, Rehman SM, Altman DG, Taggart DP. Effect of bilateral internal mammary artery grafts on long-term survival: a meta-analysis approach. Circulation. 2014;130:539-45.

14. Popovic B, Arnould MA, Selton-Suty C, et al. Comparison of two-year outcomes in patients undergoing isolated coronary artery bypass grafting with and without peripheral artery disease. Am J Cardiol. 2009;104:1377-82.

15. Norgren L, Hiatt WR, Dormandy JA, Nehler MR, Harris KA, Fowkes FG. Intersociety consensus for the management of peripheral arterial disease (TASC II). J Vasc Surg. 2007;45(Suppl S):S5-67.

16. McCaffrey DF, Griffin BA, Almirall D, Slaughter ME, Ramchand R, Burgette LF. A tutorial on propensity score estimation for multiple treatments using generalized boosted models. Stat Med. 2013;32:3388-414.

17. Wooldridge JM. Econometric analysis of cross section and panel data MIT press, Massachusetts London: The MIT Press Cambridge; vol. 108. 2002.

18. Robins JM, Hernán MÁ, Brumback B. Marginal structural models and causal inference in epidemiology. Epidemiology. 2000;11:550-60.

19. Lumley T. Analysis of complex survey samples. 2004:9(8):19.

20. Shahian DM, O'Brien SM, Sheng $S$, et al. Predictors of long-term survival after coronary artery bypass grafting surgery: results from the Society of Thoracic Surgeons adult cardiac surgery database (the ASCERT study). Circulation. 2012;125:1491-500.

21. Pevni D, Uretzky G, Mohr A, et al. Routine use of bilateral skeletonized internal thoracic artery grafting. Circulation. 2008;118:705-12.

22. Bonacchi $M$, Prifti $E$, Bugetti $M$, et al. In situ skeletonized bilateral thoracic artery for left coronary circulation: a 20-year experience. Eur J Cardiothorac Surg. 2019.

23. Nakatsu T, Tamura N, Yanagi S, Kyo S, Koshiji T, Sakata R. Bilateral internal thoracic artery grafting for peripheral arterial disease patients. Gen Thorac Cardiovasc Surg. 2014;62:481-7.

24. Tsui SS, Parry AJ, Large SR. Leg ischaemia following bilateral internal thoracic artery and inferior epigastric artery harvesting. Eur J Cardiothorac Surg. 1995;9:218-20.

25. Korkut AK, Cetin G, Suzer K. Internal thoracic artery as main blood supply to the lower limbs. Case report. Acta Chir Belg. 2006;106:243-5.

26. Shimizu T, Hirayama T, Ikeda K, Ito S, Ishimaru S. Coronary revascularization with arterial conduits collateral to the lower limb. Ann Thorac Surg. 1999;67: 1783-5.

27. Le Tanneur C, Mongardon N, Haouache H, et al. Acute lower limb ischemia after coronary artery bypass grafting. J Cardiothorac Vasc Anesth. 2015;29: 1624-6.

28. de Heer LM, Buijsrogge MP, Lahpor JR. Acute limb ischemia after internal thoracic artery harvesting: a case report. J Thorac Cardiovasc Surg. 2011;141: e5-7.

29. Adar R, Rubinstein Z, Hirshberg A. Internal mammary artery coronary bypass and leg ischemia. J Vasc Surg. 1988;7:820-1.

30. Ben-Dor I, Waksman R, Satler LF, et al. A further word of caution before using the internal mammary artery for coronary revascularization in patients with severe peripheral vascular disease! Catheter Cardiovasc Interv. 2010;75: 195-201.

31. Hirose $H$, Nakano H, Amano A, Takahashi A. Coronary artery bypass grafting for patients with aortoiliac occlusive disease. Vasc Endovasc Surg. 2002;36: 285-90.

32. Folkert IW, Foley PJ, Wang GJ, Jackson BM, Bavaria JE, Desai ND, et al. Impact of acute postoperative limb ischemia after cardiac and thoracic aortic surgery. J Vasc Surg. 2018;67(5):1530-6.e2.

33. Hardman RL, Lopera JE, Cardan RA, Trimmer CK, Josephs SC. Common and rare collateral pathways in Aortoiliac occlusive disease: a pictorial essay. Am Joentgenol. 2011;197:W519-W24.

34. Gottlob R. Ascending arteriography and evaluation of aortographic pictures. Langenbecks Arch Klin Chir Ver Dtsch Z Chir. 1954;277:483-9.

35. Hardman RL, Lopera JE, Cardan RA, Trimmer CK, Josephs SC. Common and rare collateral pathways in aortoiliac occlusive disease: a pictorial essay. AJR Am J Roentgenol. 2011;197:W519-24. 
36. Kim J, Won JY, Park SI, Lee DY. Internal thoracic artery collateral to the external iliac artery in chronic aortoiliac occlusive disease. Korean J Radiol. 2003:4:179-83

37. Yurdakul M, Tola M, Ozdemir E, Bayazit M, Cumhur T. Internal thoracic artery-inferior epigastric artery as a collateral pathway in aortoiliac occlusive disease. J Vasc Surg. 2006;43:707-13.

38. Parashara DK, Kotler MN, Ledley GS, Yazdanfar S. Internal mammary artery collateral to the external iliac artery: an angiographic consideration prior to coronary bypass surgery. Catheter Cardiovasc Diagn. 1994;32:343-5.

39. Dietzek AM, Goldsmith J, Veith FJ, Sanchez LA, Gupta SK, Wengerter KR. Interruption of critical aortoiliac collateral circulation during nonvascular operations: a cause of acute limb-threatening ischemia. J Vasc Surg. 1990;12: 645-53.

40. Kitamura S, Inoue K, Kawachi K, et al. Lower extremity ischemia secondary to internal thoracic-coronary artery bypass grafting. Ann Thorac Surg. 1993; 56:157-9.

41. Yapici F, Tuygun AG, Tarhan IA, et al. Limb ischemia due to use of internal thoracic artery in coronary bypass. Asian Cardiovasc Thorac Ann. 2002;10: 254-5.

42. Chait A. The internal mammary artery: an overlooked collateral pathway to the leg. Radiology. 1976;121:621-4

43. Subramaniam B, Singh N, Roscher C, Augoustides JG. Innovations in treating aortic diseases: the abdominal aorta. J Cardiothorac Vasc Anesth. 2012;26: 959-65.

44. Ferrer MC, Calvo I, Sánchez-Rubio J, et al. The importance of investigating the internal thoracic artery before coronary artery surgery in leriche's syndrome. Revista Española de Cardiología (English Edition). 2007;60:1198-201.

45. Feit A, Reddy CV, Cowley C, Ibrahim B, Zisbrod Z. Internal mammary artery angiography should be a routine component of diagnostic coronary angiography. Catheter Cardiovasc Diagn. 1992;25:85-90.

46. Patel P, Shammas NW, Kapalis MJ, Dippel EJ, Lemke J, Harb C. Routine visualization of the left internal mammary artery before bypass surgery: is it necessary? J Invasive Cardiol. 2005;17:479-81.

47. Biancari F, Kangasniemi OP, Mahar MA, Ylonen K. Need for late lower limb revascularization and major amputation after coronary artery bypass surgery. Eur J Vasc Endovasc Surg. 2008:35:596-602.

48. Pevni D, Ben-Gal Y, Mohr R, et al. Comparison of radial and bilateral internal thoracic artery grafting in patients with peripheral vascular diseasedagger. Interact Cardiovasc Thorac Surg. 2017;24:911-7.

49. Ruttmann E, Fischler N, Sakic A, et al. Second internal thoracic artery versus radial artery in coronary artery bypass grafting: a long-term, propensity score-matched follow-up study. Circulation. 2011;124:1321-9.

50. Gaudino M, Di Franco A, Rahouma M, et al. Unmeasured confounders in observational studies comparing bilateral versus single internal thoracic artery for coronary artery bypass grafting: a meta-analysis. J Am Heart Assoc. 2018;7.

51. Deo SV, Shah IK, Dunlay SM, et al. Bilateral internal thoracic artery harvest and deep sternal wound infection in diabetic patients. Ann Thorac Surg. 2013;95:862-9

52. Persson M, Sartipy U. Bilateral versus single internal thoracic artery grafts. Curr Cardiol Rep. 2018;20:4

53. Zhu P, Chen A, Wang Z, et al. Long-term outcomes of multiple and single arterial off-pump coronary artery bypass grafting. J Thorac Dis. 2019;11:909-19.

54. Ryan CT, Schutz A, Rosengart TK. Right for the wrong reasons: implications of data insufficiency in bilateral versus single internal thoracic artery grafting analysis. J Am Heart Assoc. 2018;7:e008262.

55. Efird JT, O'Neal WT, O'Neal JB, Ferguson TB, Chitwood WR, Kypson AP. Effect of peripheral arterial disease and race on survival after coronary artery bypass grafting. Ann Thorac Surg. 2013;96:112-8.

56. Merie C, Kober L, Olsen PS, Andersson C, Jensen JS, Torp-Pedersen C. Risk of stroke after coronary artery bypass grafting: effect of age and comorbidities. Stroke. 2012;43:38-43.

57. Loponen P, Taskinen P, Laakkonen E, Nissinen J, Luther M, Wistbacka JO. Perioperative stroke in coronary artery bypass patients. Scand J Surg. 2003; 92:148-55.

58. Neumann FJ, Sousa-Uva M, Ahlsson A, et al. 2018 ESC/EACTS Guidelines on myocardial revascularization. Eur Heart J. 2018;40:87-165.

59. Rydén L, Sartipy U, Evans M, Holzmann MJ. Acute kidney injury after coronary artery bypass grafting and long-term risk of end-stage renal disease. Circulation. 2014;130:2005-11.
60. Mariscalco G, Lorusso R, Dominici C, Renzulli A, Sala A. Acute kidney injury: a relevant complication after cardiac surgery. Ann Thorac Surg. 2011:92:1539-47.

61. Aranki S. Coronary artery bypass graft surgery. Waltham: Long-term clinical outcomes. Aldea G VE, Verrier E, Gersh B, Saperia G, Ed. In Up to Date 2020. https://www.uptodate.com/contents/coronary-artery-bypass-graft-surgeryong-term-clinical-outcomes. (Last access 24th Sept 2020).

62. Olivero JJ, Olivero JJ, Nguyen PT, Kagan A. Acute kidney injury after cardiovascular surgery: an overview. Methodist Debakey Cardiovasc J. 2012; 8:31-6.

63. Nakatsu T, Tamura N, Sakakibara Y, Hagio K, Ishigami M. Long-term survival after coronary arterial grafts in patients with end-stage renal disease. Ann Thorac Surg. 2010;90:738-43.

\section{Publisher's Note}

Springer Nature remains neutral with regard to jurisdictional claims in published maps and institutional affiliations.
Ready to submit your research? Choose BMC and benefit from:

- fast, convenient online submission

- thorough peer review by experienced researchers in your field

- rapid publication on acceptance

- support for research data, including large and complex data types

- gold Open Access which fosters wider collaboration and increased citations

- maximum visibility for your research: over $100 \mathrm{M}$ website views per year

At BMC, research is always in progress.

Learn more biomedcentral.com/submissions 